\title{
Microstructure and cellular transition characteristic of Ti-42Al-3Nb-1Mo-0.1B alloy
}

\author{
Hong Feng', Qi-bin Wang', *Shu-zhi Zhang', Chang-jiang Zhang', Fu-yin Han', Ning Cui ${ }^{2}$, Dong-dong Zhu ${ }^{3}$, \\ Duo Dong ${ }^{3}$ \\ 1. School of Materials Science and Engineering, Taiyuan University of Technology, Taiyuan 030024, China \\ 2. Key Lab of Industrial Fluid Energy Conservation and Pollution Control, Ministry of Education, Qingdao University of Technology, \\ Qingdao 266520, China \\ 3. Key Laboratory of Air-Driven Equipment Technology of Zhejiang Province, Quzhou University, Quzhou 324000, China
}

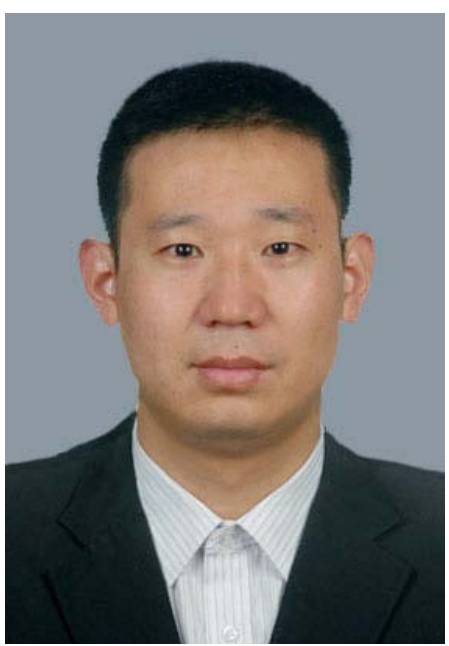

*Shu-zhi Zhang

Born in 1984. He received his Ph.D. degree in materials processing engineering from the Harbin Institute of Technology in 2013. His research interests mainly focus on intermetallic materials, including ordered L10 phase and L12 phase, and their processing technology. To date, he has published more than 60 research papers and holds 10 invent patents of China.

E-mail: shuzhizhang@outlook.com

Received: 2020-06-15

Accepted: 2020-10-20

\begin{abstract}
The microstructure and cellular transition characteristics of an intermetallic Ti-42Al-3Nb-1Mo-0.1B (at.\%) alloy were investigated. The as-cast microstructure of the alloy is mainly composed of $\left(\alpha_{2}+\gamma\right)$ lamellar structure and $(\beta+\gamma)$ mixture structure, which distributes along the boundaries of the lamellar colonies. In order to study the phase transformation of lamellar structure at aging temperature, a two-step heat treatment was carried out. After the first step of annealing treatment at $1,260{ }^{\circ} \mathrm{C}$, the microstructure with relatively finer lamellar space and $(\gamma+\beta / B 2)$ mixture structure is obtained. Aging treatment, as the second heat treatment step, has significant influence on the microstructure, attributing to a cellular reaction of $\alpha_{2}+\gamma \rightarrow \gamma+\beta$. With the increase of aging temperature, the $\left(\alpha_{2}+\gamma\right)$ lamellar structure continues to dissolve, whereas the contents of both the equiaxed $y$ and $\beta / B 2$ grains continuously increase. Besides, the orientation of lamellae $\alpha_{2}$, equiaxed $y$ and equiaxed $\beta / B 2$ in the cellular transition region follows a specific relationship of $\{0-11\}_{\beta}<1-11>_{\beta} / /\{0001\}_{\alpha 2}<2-1-10>_{\alpha 2} / /\{1-11\}_{Y}<-101>_{Y}$.
\end{abstract}

Key words: titanium aluminides; microstructure; cellular reaction; orientation relationship CLC numbers: TG146.23; Document code: A; Article ID: 1672-6421 2020)06-423-06

With the development of aircraft and automotive engines, the target material should be "stronger and lighter" to satisfy the higher practical requirements. As a kind of high temperature light-weight material, titanium-aluminum based alloys (TiAl alloy) are considered as promising new structural materials because of their excellent properties, including high specific strength and specific stiffness, and excellent high temperature oxidation resistance ${ }^{[1-3]}$. However, the poor hot deformability and the low room temperature ductility severely limit the engineering applications of TiAl based alloys ${ }^{[4-6]}$.

In order to overcome the shortcomings of TiAl alloy, Clemens et al. ${ }^{[7-9]}$ proposed a new concept of TNM alloy, which belongs to $\beta$-solidifying $\gamma$-TiAl based alloys. The composition range of TNM alloy is Ti-(42-45)Al-(3-5) Nb-(0.1-2)Mo-(0.1-1)(B, C), containing $\beta$ phase stabilizing elements $\mathrm{Nb}$ and Mo. The TNM alloy has excellent hotworkability and balanced mechanical properties when subjected to appropriate heat treatments ${ }^{[10]}$. At elevated temperature, $\beta$ phase with BCC crystal structure is softer than $\alpha_{2}$ phase and $\gamma$ phase, which enhances the thermal deformation ability of the alloy; at ambient temperature, the disordered $\beta$ phase transforms to ordered B2 phase, deteriorating the room temperature ductility ${ }^{[11-12]}$. Therefore, it is necessary to eliminate or reduce $\mathrm{B} 2$ phase to improve the ductility of the alloy at room temperature. B2 phase elimination can be achieved by heat treatment ${ }^{[13-15]}$. It is reported that the $\beta\left(\beta_{0}\right)$ phase was reduced significantly by two-step heat treatment ${ }^{[7]}$. Zhang et al. ${ }^{[16]}$ eliminated the segregation of $\beta / \mathrm{B} 2$ phase and optimized the lamellar structure of Ti-45Al-8.5Nb$0.2 \mathrm{~W}-0.2 \mathrm{~B}-0.02 \mathrm{Y}$ alloy by a two-step heat treatment. However, cellular reaction which decomposes the $\alpha_{2}+\gamma$ colony into $\alpha_{2}+\gamma+\mathrm{B} 2$ mixture structure may also occur during heat 
treatment process ${ }^{[17-18]}$. To date, few research results can be found that systematically study the cellular reaction during the heat treatment process. Therefore, in-depth study on the effect of cellular reaction on the microstructure has an important theoretical guidance for optimizing the alloy microstructure.

In this study, a two-step heat treatment was carried out for the Ti-42Al-3Nb-1Mo-0.1B (at.\%) alloy to obtain the cellular reaction microstructure. The two-step heat treatment process includes high-temperature annealing followed by air cooling and subsequent low-temperature aging treatment below the eutectoid temperature. In order to investigate the microstructure evolution and cellular transition characteristic during the heat treatment process, the precipitation relationship among $\beta / \mathrm{B} 2, \alpha_{2}$ and $\gamma$ were further analyzed.

\section{Experimental procedure}

The TNM alloy with a composition of Ti-42Al-3Nb-1Mo$0.1 \mathrm{~B}$ (at.\%) was prepared through a non-consumable vacuum arc remelting process. Subsequently, hot isostatic pressing was performed at $1,250{ }^{\circ} \mathrm{C}$ and $170 \mathrm{MPa}$ to ensure the compositional homogeneity. In order to determine the high temperature phase region of the alloy, the alloy is quenched. Figure 1 shows the microstructures of the alloy after holding at $1,220{ }^{\circ} \mathrm{C} ; 1,260{ }^{\circ} \mathrm{C} ; 1,300{ }^{\circ} \mathrm{C}$ and $1,340{ }^{\circ} \mathrm{C}$ for $30 \mathrm{~min}$ followed by water quenching. Figure 1 reveal that with the increase of holding temperature, the $(\alpha+\beta+\gamma)$ triple phase region, $(\alpha+\gamma)$ two-phase region, $\alpha$ single phase region and $(\alpha+\beta)$ two-phase region appear successively. Combined with the
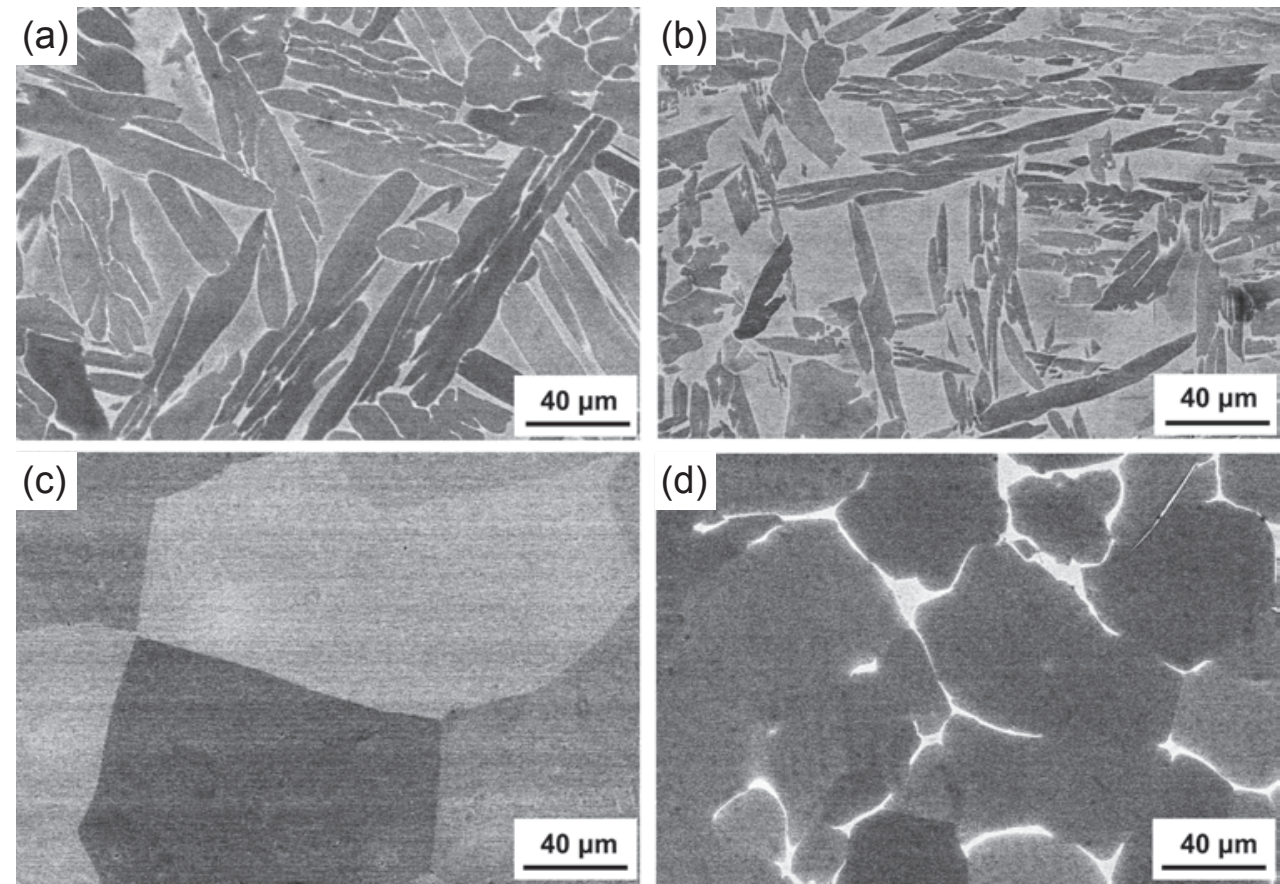

Fig. 1: Microstructures of the alloy after annealing at different temperatures for $\mathbf{3 0} \mathrm{min}$ followed by water quenching: (a) $1,220^{\circ} \mathrm{C}$, the $(\alpha+\beta+\gamma)$ triple-phase region; (b) $1,260^{\circ} \mathrm{C},(\alpha+\gamma)$ two-phase region; (c) $1,300^{\circ} \mathrm{C}$, $\alpha$ single phase region and $(d) 1,340{ }^{\circ} \mathrm{C},(\alpha+\beta)$ two-phase region

phase diagram of Ti-(41-45)Al-4Nb-1Mo-0.1B alloy ${ }^{[19]}$, the solidifying pathway of the experimental alloy is analyzed as follows: $L \rightarrow L+\beta \rightarrow \beta \rightarrow \beta+\alpha \rightarrow \alpha \rightarrow \alpha+\gamma \rightarrow \alpha+\beta+\gamma \rightarrow \alpha_{2}+\beta / B 2+\gamma$. Therefore, the solidification path completely passes through the single $\beta$ phase region, avoiding the peritectic reaction ${ }^{[10]}$.

After hot isostatic pressing, the two-step heat treatment was carried out. In the first step, the two-phase region $\left(1,260{ }^{\circ} \mathrm{C}\right)$ is selected to reduce the $\beta / \mathrm{B} 2$ phase at the grain boundary of lamellar structure. As shown in Fig. 2, the first-step heat treatment was annealing in the $\alpha+\gamma$ phase region at $1,260{ }^{\circ} \mathrm{C}$ and held for $30 \mathrm{~min}$, then air cooled (AC) to acquire finer lamellar structures. Then, the second step was performed, i.e., aging treatment at different temperatures $\left(1,000{ }^{\circ} \mathrm{C} ; 1,050{ }^{\circ} \mathrm{C}\right.$ and $1,100{ }^{\circ} \mathrm{C}$ ) for $6 \mathrm{~h}$ followed by furnace cooling (FC). All the heat treatment samples were wire-cut with a dimension of $4 \mathrm{~mm} \times 8 \mathrm{~mm} \times 10 \mathrm{~mm}$.

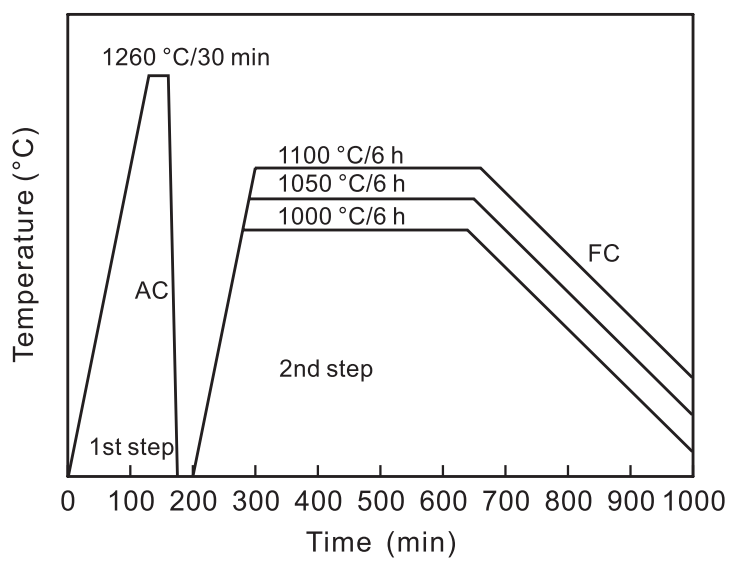

Fig. 2: Schematic drawing of the experimental two-step heat treatment process 
The microstructure was investigated using the TESCAN Mira3 LMH scanning electronic microscopy with the back scattered electron (BSE) mode. In addition, phase analysis was performed by means of X-ray diffraction (XRD) on the Ultima IV (RIGAKU, Japan) in the range of $20^{\circ}-80^{\circ}(2 \theta)$ with a step size of $0.02^{\circ}$. In order to investigate the details of microstructure evolution and cellular reaction characteristic, electron back scattered diffraction (EBSD) technique (Quanta 200FEG SEM) was employed. All samples were prepared by electrolytic polishing with a voltage of $30 \mathrm{~V}$ at -5 to $-10{ }^{\circ} \mathrm{C}$ for EBSD. The electrolytic polishing liquid was composed of $60 \%$ methanol, $30 \%$ butanol and 10\% perchloric acid (vol.\%).

\section{Results and discussion}

\subsection{As-cast microstructure}

Figure 3 shows a nearly lamellar structure of the as-cast Ti-

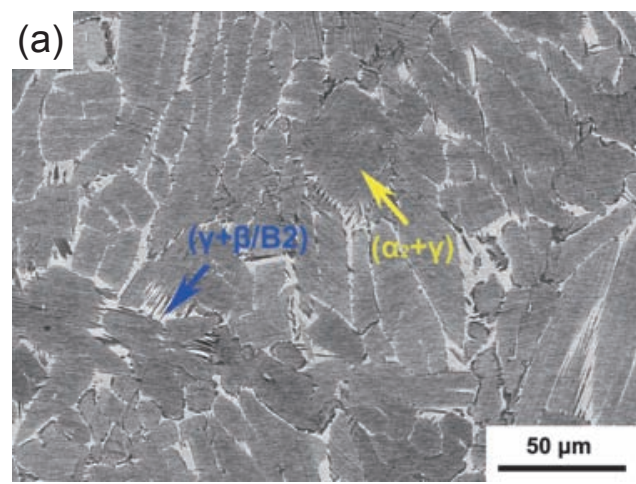

42Al-3Nb-1Mo-0.1B alloy. Figure 3(b) shows the XRD result of the alloy, indicating the appearance of $\alpha_{2}, \gamma$ and $\beta / B 2$. In the BSE mode (Fig. 2a), $\beta / \mathrm{B} 2$ phase has the brightest contrast, $\alpha_{2}$ phase is grey while $\gamma$ is black ${ }^{[20]}$. The as-cast microstructure is composed of $\left(\alpha_{2}+\gamma\right)$ lamellar colonies (marked by yellow arrow) and $(\gamma+\beta / \mathrm{B} 2)$ mixture structure (marked by blue arrow), which distributes along the boundaries of the lamellar colonies. The $\left(\alpha_{2}+\gamma\right)$ lamellar colonies are formed by a transformation of $\alpha \rightarrow \alpha_{2}+\gamma$ in TiAl based alloys ${ }^{[21]}$, and the fine $\gamma$ grain in the $(\gamma+\beta / B 2)$ mixture structure is caused by decomposition of the residual $\beta$ phase, which is thermodynamically unstable during the cooling process ${ }^{[9,22]}$. Previous research shows that ordered B2 phases located at the boundaries of lamellar colonies will transform to disordered $\beta$ phase at high temperature, which is conducive to the deformability of TiAl based alloy by providing an independent slip system ${ }^{[23-26]}$

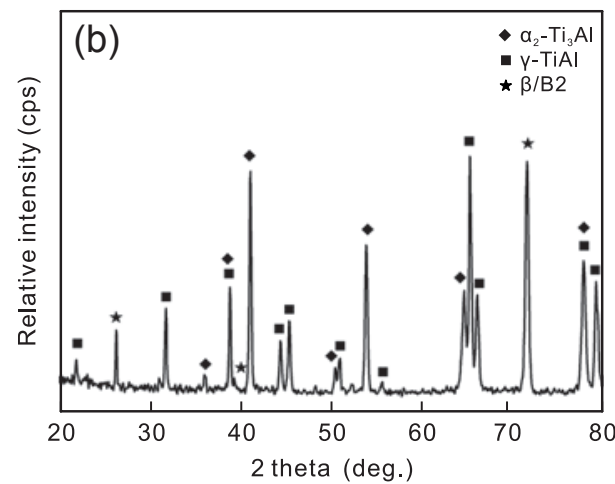

Fig. 3: As-cast microstructure (a) and XRD result (b) of Ti-42Al-3Nb-1Mo-0.1B alloy

\subsection{Heat treated microstructures}

Figure 4 shows the microstructure after annealing at $1,260{ }^{\circ} \mathrm{C}$ for $30 \mathrm{~min}$ and then air cooled. It can be found that the annealed microstructure consists of $\left(\alpha_{2}+\gamma\right)$ lamellar colonies and $(\gamma+\beta /$ B2) mixture structure distributed along the boundary of lamellar colonies. Compared with the as-cast microstructure, the content of $\beta / \mathrm{B} 2$ phase of annealed microstructure decreases, whereas the content of $\gamma$ at the boundaries of lamellar structure increases. After annealing at $1,260{ }^{\circ} \mathrm{C}$, the samples were subsequently aging treated at different temperatures. Figure 5 shows the microstructures of the aging treated samples. As shown in Fig. 5(a), the $(\gamma+\beta / B 2)$ mixture structure which locates at the boundaries of the lamellar colonies, after aging treatment at $1,000{ }^{\circ} \mathrm{C}$ for $6 \mathrm{~h}$, is more discontinuous than that of samples annealed at $1,260{ }^{\circ} \mathrm{C}$. When the aging temperature reaches $1,050{ }^{\circ} \mathrm{C}$ [Fig. 5(b)], the content of $\beta / \mathrm{B} 2$ phase increases significantly and the $\gamma$ grain grows up. Additionally, $\beta / \mathrm{B} 2$ phase block is gradually dissolved by $\gamma$ particles. With the further increase of aging temperature, the $\left(\alpha_{2}+\gamma\right)$ lamellar colonies continue to dissolve, whereas both the volume fraction and size of the equiaxed $\gamma$ and $\beta / \mathrm{B} 2$ grains increase continuously. This transformation is attributed to a cellular reaction of $\alpha_{2}+\gamma \rightarrow \gamma+\beta$ during the aging treatment ${ }^{[12]}$, which results in the decrease of $\left(\alpha_{2}+\gamma\right)$ lamellar colonies and the increase of $(\gamma+\beta / B 2)$ mixture structure. The driving force of the cellular reaction is provided by the residual stress, the high interface energy inside the fine lamellar structure, and the strong chemical disequilibrium ${ }^{[27-28]}$. With the aging temperature increasing to $1,100{ }^{\circ} \mathrm{C}$, significant lamellar structure coarsening and lamellae spacing increasing are observed, as shown in Fig. 5(c). Besides, the coarsening lamellar structure shows different orientation with the primary lamellar structure [Fig. 5(d)]. This is the discontinuous coarsening phenomenon of primary lamellae ${ }^{[29-31]}$. The coarsening lamellar structure in turn reduces the driving force of the cellular reaction.

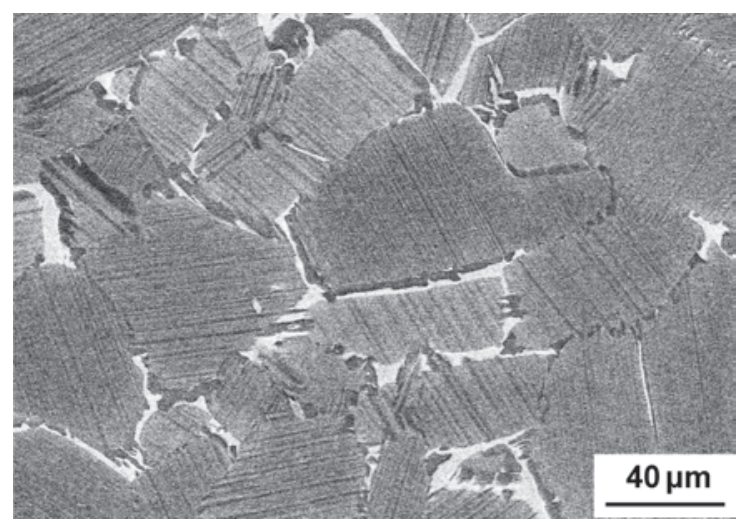

Fig. 4: Microstructure of the alloy annealed at $1,260^{\circ} \mathrm{C}$ for $30 \mathrm{~min}$ and then air cooled 

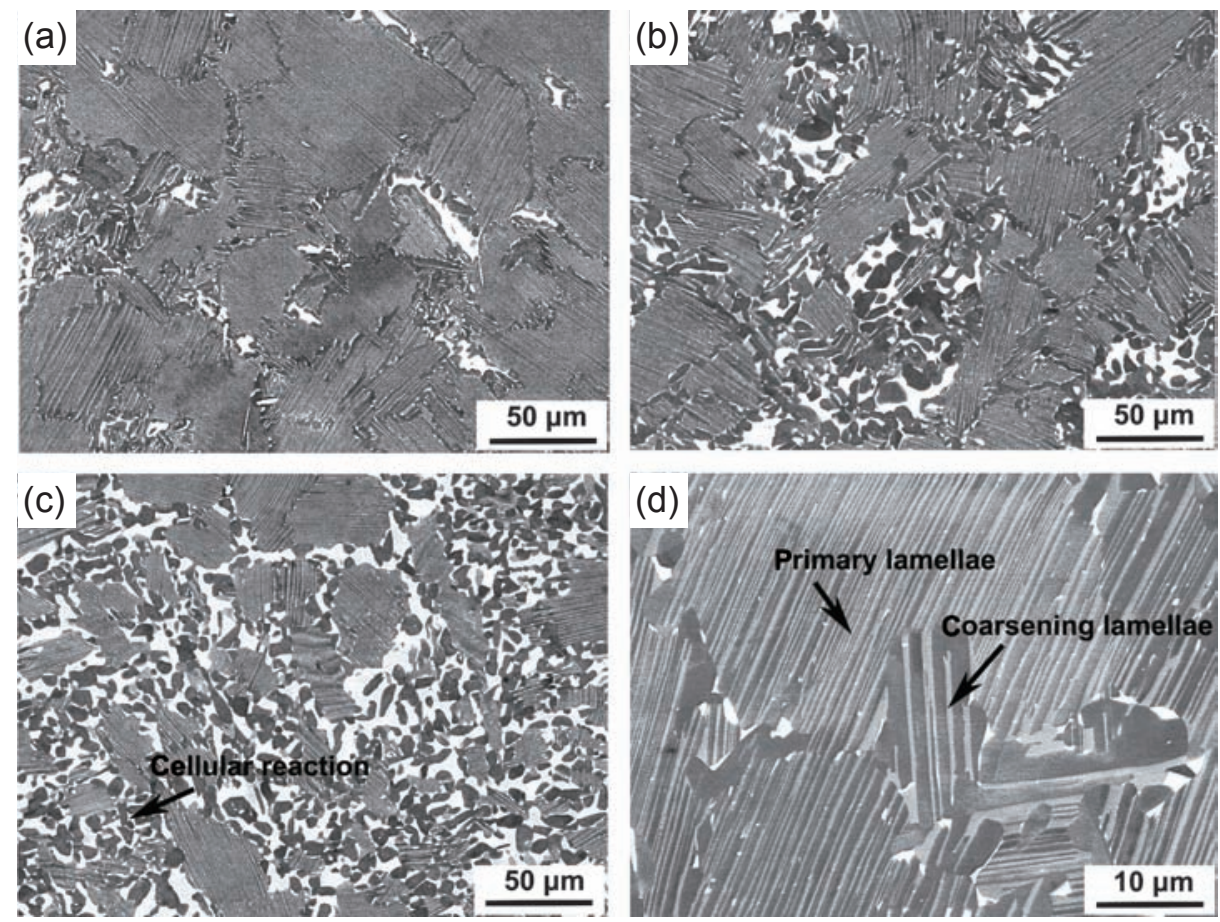

Fig. 5: Microstructure evolution of cellular reaction at various aging temperatures: (a) $1,000{ }^{\circ} \mathrm{C} / 6 \mathrm{~h}$; (b) $1,050^{\circ} \mathrm{C} / 6 \mathrm{~h}$; (c) $1,100{ }^{\circ} \mathrm{C} / 6 \mathrm{~h}$ and (d) the discontinuous coarsening at $1,100^{\circ} \mathrm{C} / 6 \mathrm{~h}$

In order to further study the cellular transition characteristic, EBSD was used. Figure 6 shows the phase constitution maps of the alloy aged at various temperatures. The results show that $\beta /$ B2 phase appears inside the lamella, which is more obvious with the increase of aging temperature. This is due to the occurrence of cellular reaction, resulting in the continuous consumption of lamellaer structure and the increase of the equiaxed $\beta / \mathrm{B} 2$ and $\gamma$ phases. With the aging temperature increasing from $1,000{ }^{\circ} \mathrm{C}$ to $1,050{ }^{\circ} \mathrm{C}$ [Figs. 6(a) and (b)], the proportion of $\beta /$ B2 phase increases from $5.74 \%$ to about $8.01 \%$. With the further increase of aging temperature [Fig. 6(c)], the $\beta / B 2$ phase significantly increases to $25.1 \%$ at $1,100{ }^{\circ} \mathrm{C}$. It can be explained that the increase of $\beta$ phase is caused by cellular reaction, and the cellular reaction is promoted with the increase of aging temperature. The cellular transition characteristic is further discussed by selected specimen aged at $1,050{ }^{\circ} \mathrm{C}$ for $6 \mathrm{~h}$. Figure 7 shows the inverse pole figure (IPF) and the corresponding pole figure $(\mathrm{PF})$ of the present alloy aged at $1,050{ }^{\circ} \mathrm{C}$ for $6 \mathrm{~h}$. The color represents the grain orientation in the IPF map [Fig. 7(a)]. As shown in Fig. 7(b), comparing with $\beta / \mathrm{B} 2$ grain, the distribution of $\gamma$ grain in $\{111\}_{\gamma} \mathrm{PF}$ is relative random, which is attributed to the various variant selection during the precipitation of $\gamma$ phase. According to the previous study, twenty-four oriented $\gamma$ variants are precipitated in $\beta$ matrix in accordance with K-S orientation relationship, and two twin-related $\gamma$ variants are formed in $\alpha_{2}$ phase according to Blackburn orientation relationship ${ }^{[31-33]}$. The orientation relationship of $\alpha_{2}, \beta / \mathrm{B} 2$ and $\gamma$ is further discussed in Fig. 8.
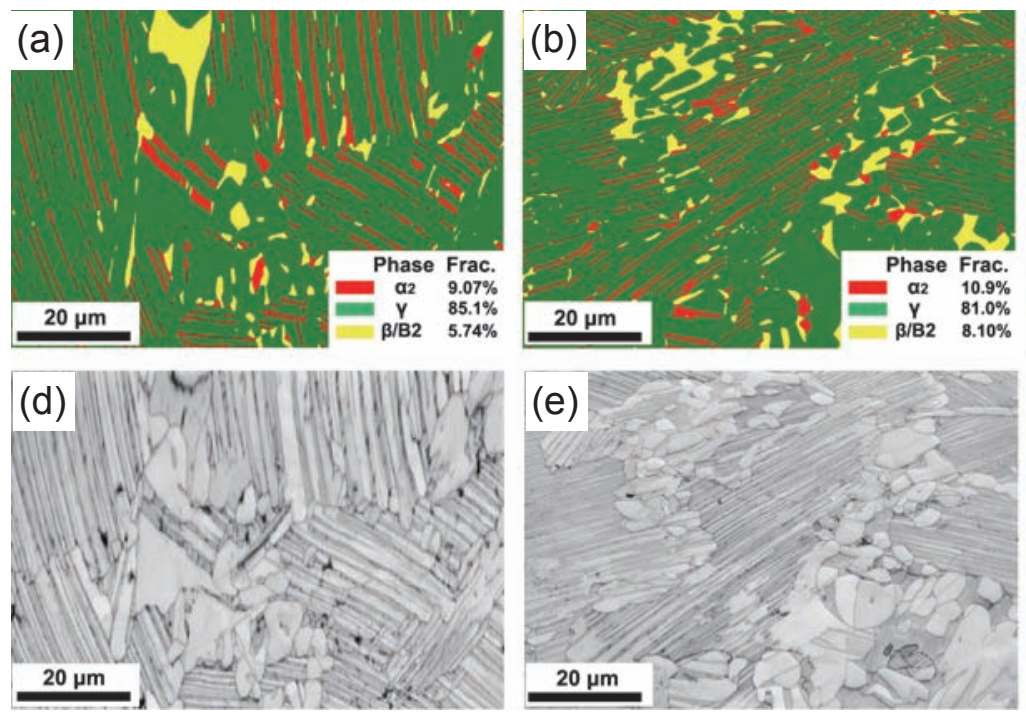

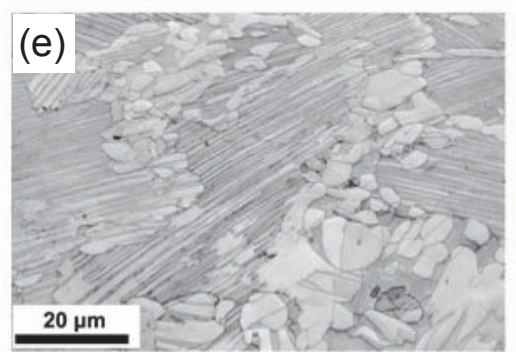

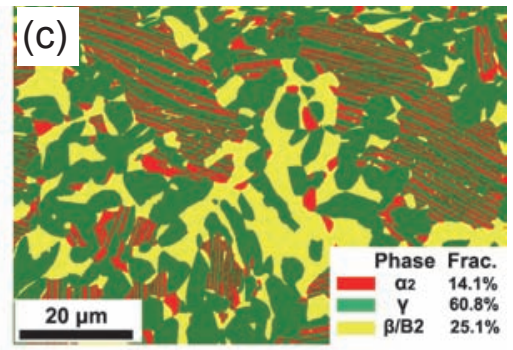

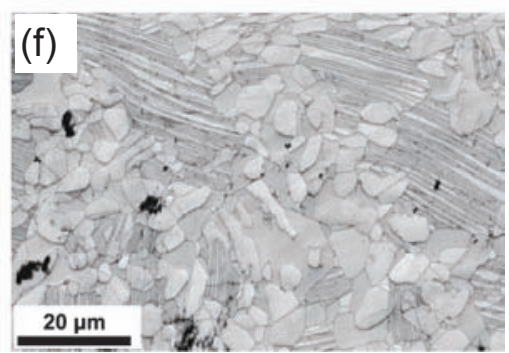

Fig. 6: Phase constitution maps (a-c) and corresponding band contrast maps (d-f) of the present alloy aged at various temperatures: (a, d) $1,000^{\circ} \mathrm{C} / 6 \mathrm{~h}$; (b, e) $1,050{ }^{\circ} \mathrm{C} / 6 \mathrm{~h}$; (c, f) $1,100^{\circ} \mathrm{C} / 6 \mathrm{~h}$ 
(a)

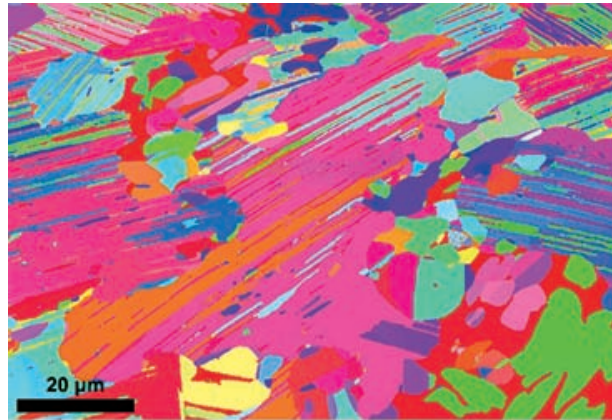

(b)
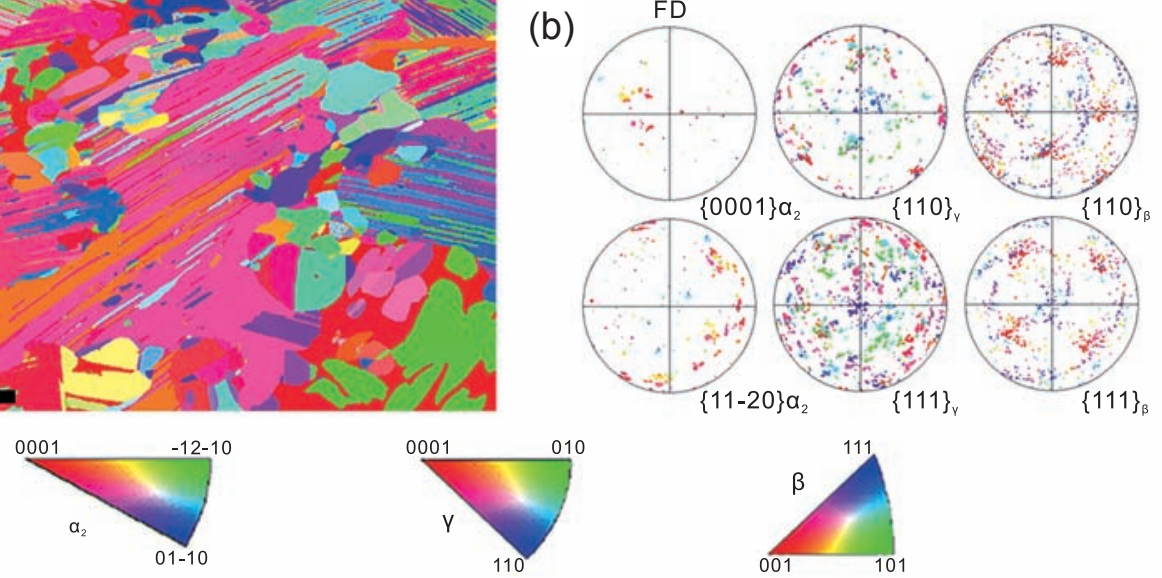

Fig. 7: EBSD analysis of the alloy aged at $1,050^{\circ} \mathrm{C}$ for $6 \mathrm{~h}$ : (a) IPF map and (b) corresponding PF maps of $\alpha_{2}, Y$ and $\beta$, respectively

In Fig. 8, the IPF overlapped with the corresponding band contrast (BC) of the alloy aged at $1,050{ }^{\circ} \mathrm{C}$ for $6 \mathrm{~h}$ shows the grain orientation relationship of the involved phases $(\beta / \mathrm{B} 2$, $\alpha_{2}$ and $\gamma$ ) in cellular reaction. Obviously, the microstructure in the black dotted rectangle in Fig. 8(b) is formed by cellular reaction. Three grains are selected (G1, G2 and G3) in the black rectangle (G1 is lamellae $\alpha_{2}$ grain, G2 is equiaxed $\gamma$ grain, and $\mathrm{G} 3$ is equiaxed $\beta / \mathrm{B} 2$ grain). The positional relationship of Grains G1, G2 and G3 is illustrated in Fig. 8(d), and the corresponding pole figure is shown in Fig. 8(e). The orientation relationship of the $\left(\alpha_{2}+\gamma\right)$ lamellar structure in TiAl alloy follows the traditional Blackburn orientation relationship $\left(\{111\}_{\gamma} / /\{0001\}_{\alpha},<1-10>_{\gamma} / /<11-20>_{\alpha}\right)^{[31-32]}$. Figure 8(e) shows the G1, G2 and G3 in cellular transition region following an orientation relationship of $\{110\}_{\beta}<111>_{\beta} / /(0001)_{\alpha_{2}}[2-1-10]_{\alpha_{2}} / /$ $\{111\}_{\gamma}\left\langle 110>_{\gamma}\right.$, which is named K-S relationship ${ }^{[33]}$. Meanwhile, Figure 8(f) depicts the three-dimensional crystallographic relationship of the lamellae $\alpha_{2}$ grain, equiaxed $\beta / \mathrm{B} 2$ grain and $\gamma$ grain, in which the blue platform and the red arrow indicate the orientation relationships of $\{0001\}_{\alpha_{2}} / /\{1-11\}_{\gamma} / /\{0-11\}_{\beta B B 2}$ and $<2-1-10>\alpha_{2} / /<-101>_{\gamma} / /<1-11>_{\beta B 2}$, respectively.

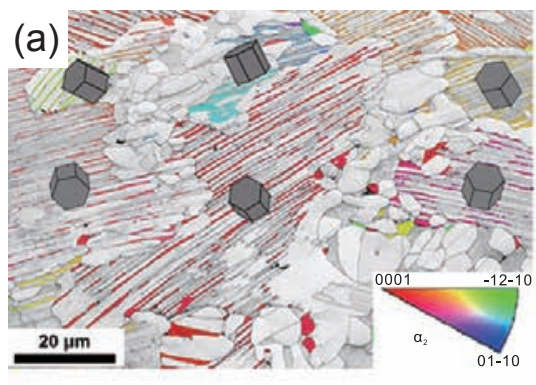

(d) Cellular reaction:

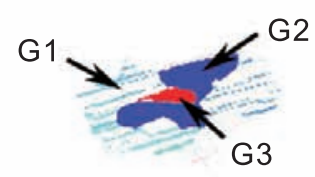

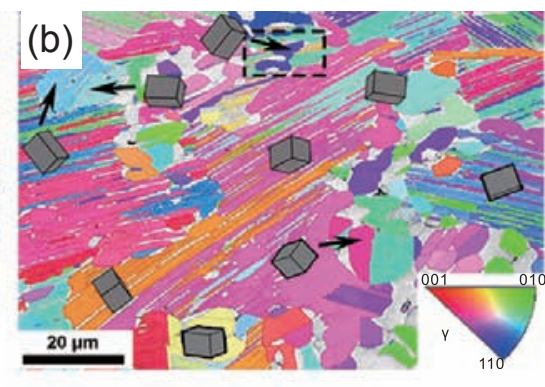

(e)

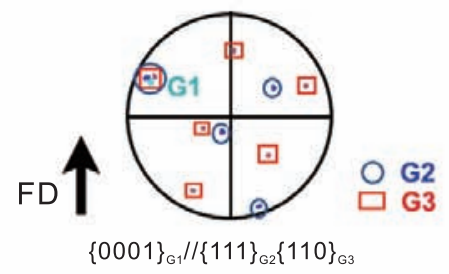

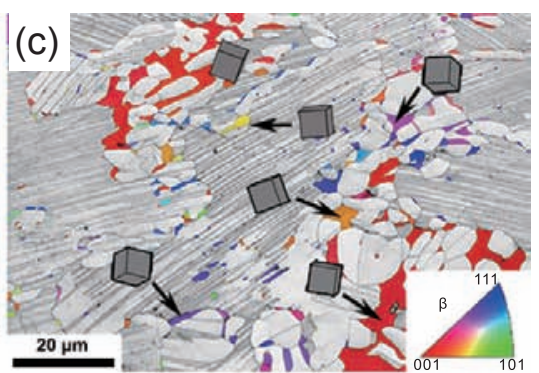

(f)

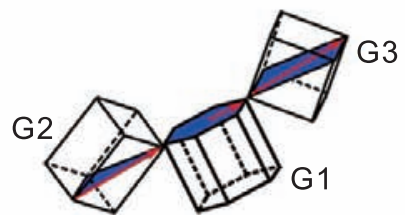

$\{0001\}_{\mathrm{G} 1}<2-1-10>_{\mathrm{G} 1} / /\{1-11\}_{\mathrm{G} 2}<-101>_{\mathrm{G} 2}$ $/ /\{0-11\}_{\mathrm{G} 3}<1-11>_{\mathrm{G} 3}$

Fig. 8: EBSD analysis of the alloy aged at $1,050^{\circ} \mathrm{C}$ for $6 \mathrm{~h}$ : (a-c) IPF maps overlapped with the corresponding BC maps respectively: (a) $\alpha_{2}$ phase, (b) Y phase and (c) $\beta$ phase; (d) IPF maps of selected grains and corresponding orientations exhibit in (e); (f) three-dimensional crystallographic relationship

\section{Conclusions}

The microstructure evolution and cellular transition characteristic of Ti-42Al-3Nb-1Mo-0.1B alloy after a two-step heat treatment were investigated. The following conclusions are drawn from the obtained results:

(1) With an increase in quenching temperature from $1,220{ }^{\circ} \mathrm{C}$ to $1,340{ }^{\circ} \mathrm{C},(\alpha+\beta+\gamma)$ triple phase region, $(\alpha+\gamma)$ two-phase region, $\alpha$ single phase region and $(\alpha+\beta)$ two-phase region appear successively. The solidifying pathway of Ti-42Al-3Nb-1Mo-0.1B alloy is: $\mathrm{L} \rightarrow \mathrm{L}+\beta \rightarrow \beta \rightarrow \beta+\alpha \rightarrow \alpha \rightarrow \alpha+\gamma \rightarrow \alpha+\beta+\gamma \rightarrow \alpha_{2}+\beta / \mathrm{B} 2+\gamma$.

(2) The microstructure of the as-cast Ti-42Al-3Nb-1Mo$0.1 \mathrm{~B}$ alloy mainly consists of the $\left(\alpha_{2}+\gamma\right)$ lamellar structure and 
the $(\beta / \mathrm{B} 2+\gamma)$ mixture, which distributes along the boundaries of the lamellar colonies.

(3) After the two-step heat treatment (annealing at $1,260{ }^{\circ} \mathrm{C}$ for $30 \mathrm{~min}$, air cooling + aging at different temperatures for $6 \mathrm{~h}$ and then furnace cooling), the lamellar structure is decomposed by a cellular reaction of $\alpha_{2}+\gamma \rightarrow \gamma+\beta$. With the increase of aging temperature, the $\left(\alpha_{2}+\gamma\right)$ lamellar structure continues to dissolve, whereas both the volume fraction and size of the equiaxed $\gamma$ and $\beta / \mathrm{B} 2$ grains are increasing continuously.

(4) The orientation relationship of $\alpha_{2}, \gamma$ and $\beta / B 2$ in the cellular transition region follows a K-S relationship of $\{0-11\}_{\beta}<1-11>_{\beta} / /$ $\{0001\}_{\alpha_{2}}<2-1-10>\alpha_{2} / /\{1-11\}_{\gamma}<-101>_{\gamma}$ after aging heat treatment.

\section{Acknowledgements}

This work was financially supported by the National Natural Science Foundation of China (Grant Nos.: 52071228, 51704174 , 51801112), the Natural Science Foundation of Shanxi Province (Grant Nos.: 201903D121056 and 201903D421084), and the Shandong Province Key Research and Development Program (Grant No.: 2019GGX102045).

\section{References}

[1] Zhang S Z, Zhao Y B, Zhang C J, et al. The microstructure, mechanical properties, and oxidation behavior of beta-gamma TiA alloy with excellent hot workability. Mater. Sci. Eng. A, 2017, 700: 366-373.

[2] Zhang S Z, Zhang C J, Du Z X, et al. Microstructure and tensile properties of hot forged high $\mathrm{Nb}$ containing TiAl based alloy with initial near lamellar microstructure. Mater. Sci. Eng. A, 2015, 642: 16-21.

[3] Yang J R, Cao B, Wu Y L, et al. Continuous cooling transformation (CCT) behavior of a high Nb-containing TiAl alloy. Materialia, 2019, 5: 100169.

[4] Yang J R, Wang $X Y$, Cao B, et al. Tailoring the microstructure of a $\beta$-solidifying TiAl alloy by controlled post-solidification isotherma holding and cooling. Metall. Mater. Trans. A, 2017, 48 (10): 1-11.

[5] Schwaighofer E, Clemens $\mathrm{H}$, Mayer S, et al. Microstructural design and mechanical properties of a cast and heat-treated intermetallic multi-phase $\mathrm{y}$-TiAl based alloy. Intermetallics, 2014, 44: 128-140.

[6] Yang J R, Chen R R, Ding H S, et al. Heat transfer and macrostructure formation of $\mathrm{Nb}$ containing TiAl alloy directionally solidified by square cold crucible. Intermetallics, 2013, 42: 184-191.

[7] Clemens $\mathrm{H}$, Wallgram W, Kremmer S, et al. Design of novel $\beta$-solidifying TiAl alloys with adjustable $\beta / B 2-p h a s e$ fraction and excellent hot workability. Adv. Eng. Mater., 2008, 10: 707-713.

[8] Wallgram W, Schmölzer T, Cha L. Technology and mechanical properties of advanced $\mathrm{Y}$-TiAl based alloy. Int. J. Mater. Res., 2009, 100(8): 1021-1030.

[9] Clemens $\mathrm{H}$, Chladil H F, Wallgram W, et al. In and ex situ investigations of the $\beta$-phase in a $\mathrm{Nb}$ and Mo containing $\mathrm{\gamma}$-TiAl based alloy. Intermetallics, 2008, 16(6): 827-833.

[10] Clemens H, Mayer S. Design, processing, microstructure properties, and applications of advanced intermetallic TiAl alloys. Adv. Eng. Mater., 2013, 15(4): 191-215.

[11] Imayev V M, Imayev R M, Khismatullin T G. Mechanical properties of the cast intermetallic alloy Ti-43Al-7( $\mathrm{Nb}, \mathrm{Mo})-0.2 \mathrm{~B}$ (at.\%) after heat treatment. Phys. Metals Metallogr., 2008, 105(5): 484-490.

[12] Gaitzenauer A, Stark A, Gosslar D, et al. Microstructure and texture evolution in an intermetallic $\beta$-stabilized TiAl alloy during forging and subsequent isothermal annealing. Adv. Eng. Mater., 2014, 16: 445-451.
[13] Huang J S, Huang L, Zhang $Y \mathrm{H}$, et al. Effect of heat treatment on microstructure of Ti-45Al-7Nb-0.15B-0.7W alloy. T. Mater. Heat Treat., 2006, 27(6): 78-83. (In Chinese)

[14] Wu X H. Review of alloy and process development of TiAl alloys. Intermetallics, 2006, 14: 1114-1122.

[15] Kastenhuber M, Rashkova B, Clemens H, et al. Effect of microstructural instability on the creep resistance of an advanced intermetallic $Y$-TiAl based alloy. Intermetallics, 2017, 80: 1-9.

[16] Zhang $\mathrm{Y}, \mathrm{Kou} \mathrm{H}$, Yang G, et al. A two-step heat treatment to eliminate the micro-segregation of Ti-45Al-8.5Nb-0.2W-0.2B-0.02Y alloy. Adv. Eng. Mater., 2016, 18: 1267-1272.

[17] Cha L, Clemens H, Dehm G. Microstructure evolution and mechanical properties of an intermetallic Ti-43.5Al-4Nb-1Mo-0.1B alloy after ageing below the eutectoid temperature. Int. J. Mater. Res., 2011, 102(6): 703-708.

[18] Bolz S, Oehring M, Lindemann J, et al. Microstructure and mechanical properties of a forged $\beta$-solidifying $y$ TiAl alloy in different heat treatment conditions. Intermetallics, 2015, 58: 71-83.

[19] Clemens H, Boeck B, Wallgram W, et al. Experimental studies and thermodynamic simulations of phase transformations in Ti-(41-45) Al-4Nb-1Mo-0.1B alloys. MRS Proceedings, 2008, doi:10.1557/ proc-1128-u03-06

[20] Dong S L, Liu T, Li Y J, et al. Hot deformation processing capability of Fe-contained high Nb TiAl-based alloy. Vacuum, 2019, 159 391-399.

[21] Takeyama M, Kobayashi S. Physical metallurgy for wrought gamma titanium aluminides: Microstructure control through phase transformations. Intermetallics, 2005, 13(9): 993-999.

[22] Clemens $\mathrm{H}$, Chladil $\mathrm{H}$, Wallgram $\mathrm{W}$, et al. In and ex-situ investigations of the $\beta$-phase in a $\mathrm{Nb}$ and Mo containing $\gamma$-TiAl based alloy. Intermetallics, 2008, 16: 827-833

[23] Schmoelzer T, Liss K, Zickler G A, et al. Phase fractions, transition and ordering temperatures in TiAl-Nb-Mo alloys: an in-and exsitu study. Intermetallics, 2010, 18(8): 1544-1552.

[24] Schwaighofer E, Rashkova B, Clemens H, et al. Effect of carbon addition on solidification behavior, phase evolution and creep properties of an intermetallic $\beta$-stabilized $\gamma$-TiAl based alloy. Intermetallics, 2014, 46: 173-184.

[25] Tang B, Cheng L, Kou H C, et al. Hot forging design and microstructure evolution of a high $\mathrm{Nb}$ containing $\mathrm{TiAl}$ alloy. Intermetallics, 2015, 58: 7-14.

[26] Liss K, Schmoelzer T, Yan K, et al. In situ study of dynamic recrystallization and hot deformation behavior of a multiphase titanium aluminide alloy. J. Appl. Phys., 2009, 106: 1139-1234.

[27] Denquin A, Naka S. Phase transformation mechanisms involved in two-phase TiAl-based alloys - lamellar structure formation. Acta Mater., 1996, 44(1): 343-352.

[28] Tałach-Dumańska M, Zięba P, Pawłowski A, et al. Practical aspects of discontinuous precipitation and dissolution. Mater. Chem. Phys., 2003, 80(2): 476-481.

[29] Wang $X P$, Zheng $Y R$. Discontinuous coarsening of $\mathrm{Ti}_{3} \mathrm{Al}+\mathrm{TiAl}$ lamellae. Chin. J. Nonferrous Met., 1998, 8: 233-238.

[30] Wang $X P$, Zheng $Y$ R. Discontinuous coarsening transformations in TiAl based alloys. J. Mater. Eng., 2000, 7: 20-23.

[31] Shong D S, Kim Y W. Discontinuous coarsening of high perfection lamellae in titanium aluminides. Scripta Metallurgica, 1989, 23(2): 257-261.

[32] Wang Q B, Zhang S Z, Zhang C J, et al. Effect of hot rolling temperature on microstructure evolution, deformation texture and nanoindentation properties of an intermetallic Ti-43Al-9V-0.2Y alloy. Intermetallics, 2020, 117: 106677.

[33] Cheng $\mathrm{T} T$, Loretto $\mathrm{M} \mathrm{H}$. The decomposition of the beta phase in Ti-44AI-8Nb and Ti-44Al-4Nb-4Zr-0.2 Si alloys. Acta Mater., 1998 46(13): 4801-4819.

[34] Chen $Y$, Cheng L, Sun L Y, et al. Characterization of a new microstructure in a $\beta$-solidifying TiAl alloy after air-cooling from a $\beta$ phase field and subsequent tempering. Metals, 2018, 8: 156-166. 